\title{
BERAGAM GAMBARAN MENGENAI ETNIS KETURUNAN CINA \\ PADA KARYA TERJEMAHAN KEVIN KWAN'S KEKASIH KAYA \\ RAYA
}

The Different Portrayals of the Chinese in Kevin Kwan's Kekasih Kaya Raya Translated

Novel

\author{
Galant Nanta Adhitya ${ }^{1}$, Nandy Intan Kurnia ${ }^{2}$ \\ ${ }^{1}$ Fakultas Ilmu Budaya, Universitas Gadjah Mada \\ Jl. Nusantara 1, Bulaksumur, Catur Tunggal, Kec. Depok, Kabupaten Sleman, Daerah \\ Istimewa Yogyakarta \\ Email: galant.nanta@me.com

\begin{abstract}
${ }^{2}$ Fakultas Bahasa dan Seni, Universitas Negeri Yogyakarta
Jl. Colombo No.1, Caturtunggal, Kec. Depok, Kabupaten Sleman,

Daerah Istimewa Yogyakarta

Email: nandy_intankurnia@uny.ac.id
\end{abstract}

\begin{abstract}
Abstrak: Penelitian ini berkaitan dengan topik multikulturalisme pada karya sastra dengan menunjukkan beragam penggambaran yang berbeda antara keturunan Cina Amerika, Cina Singapura dan Cina Daratan, pada karya Kevin Kwan yang telah diterjemahkan, yakni berjudul Kekasih Kaya Raya. Penelitian ini adalah penelitian deskriptif kualitatif. Data dari penelitian ini adalah dalam bentuk fitur-fitur kebahasaan yang terdapat pada karya, Kekasih Kaya Raya, seperti kata, frase, klausa, kalimat dan paragraf yang berkaitan dengan topik multikulturalisme. Hasil penelitian adalah sebagai berikut: (1) keturunan Cina Amerika digambarkan sebagai sosok yang hemat dan egaliter; (2) keturunan Cina Singapura digambarkan tertutup dan komunis-individualis; dan (3) keturunan Cina daratan digambarkan boros dan menganut paham Konfusius-Komunis.
\end{abstract}

Kata kunci: karya sastra, multikulturalisme, keturunan Cina daratan, keturunan Cina Singapura, keturunan Cina Amerika

Abstract: This research aims to discuss the topic of multiculturalism in literary texts by showing the different portrayals of the Chinese, especially the American Chinese, Singaporean Chinese and Mainland Chinese as seen in Kevin Kwan's translated novel, 
Kekasih Kaya Raya. This is a descriptive qualitative research. The data are in the form of language features, such as words, phrases, clauses, sentences and paragraph related to multiculturalism expressed in China Rich Girlfriend. The findings are as follows: (1) the American Chinese are portrayed as frugal and egalitarian; (2) the Singaporean Chinese are secretive and mixed communitarian-individualist; and (3) the Mainland Chinese are spendthrifty and believe in Confucius-Communist.

Keywords: Literary text, Multiculturalism, Mainland Chinese, Singaporean Chinese, American Chinese

\section{Pendahuluan}

Perbedaan latar-belakang, cara pandang seseorang ataupun kelompok terhadap ras, ideologi, atau kepercayaan, biasanya akan menimbulkan goncangan-goncangan dalam kehidupan bermasyarakat. Salah satu persoalan yang belakangan ini harus dialamai oleh banyak negara di berbagai belahan dunia, termasuk juga Indonesia, adalah mengenai persoalan rasisme antiCina. Seperti yang tercantum pada artikel yang berjudul "Rasisme terhadap Etnis Tionghoa dari Masa ke Masa”, persoalan yang berkaitan dengan rasisme itu sendiri sering terjadi karena adanya kecemburuan, gesekan, dan konflik yang timbul di masyarakat dipandang sebagai sebuah persoalan yang berakar dari hal-hal yang sesungguhnya tidak berhubungan sama sekali, salah satunya adalah mengenai persoalan identitas dan rasial (Dhani, 2016).

Dalam kasus rasisme di Indonesia, menurut Freedman (Dhani, 2016) "kebencian terhadap etnis Tionghoa merupakan hasil dari politik pecah belah Soeharto.” Ia juga menambahkan, "Soeharto memaksa masyarakat Indonesia untuk melakukan asimilasi sembari mengidentifikasi mereka sebagai bukan pribumi” (Dhani, 2016).

Penyematan sebutan sebagai "orang Cina" pada kasus di Indonesia sebenarnya tidak tepat, karena seperti yang diketahui bersama "orang Cina" yang ada di Indonesia bukanlah warga negara Republik Rakyat Cina (RRC), melainkan hanyalah keturunan.

Seperti yang diketahui bersama, RRC adalah sebuah negara yang sangat luas, dan warga negaranya tersebar ke berbagai belahan dunia. Kesalah-pahaman mengenai pengunaan terminologi "Cina", tidak hanya dapat ditemukan di Indonesia, melainkan juga dapat ditemukan dengan mudahnya di berbagai negara lainnya. Bagi beberapa orang, penyebutan kata “Cina” merujuk pada warga negara RRC, 
dan tentu saja hal ini tidaklah tepat. Seperti yang sampaikan oleh Wang, setidaknya yang disebut sebagai "orang Cina" dapat dibagi menjadi 2 tipe. Yang pertama adalah orang Cina Daratan (berasal dari

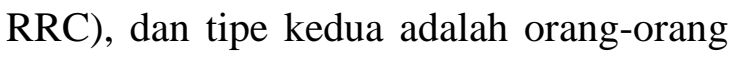
Cina yang keluar dari RRC, bahkan sebelum RRC menganut paham komunis. Tipe kedua ini biasanya tinggal di negaranegara Asia Pasifik, seperti Amerika Serikat dan Singapura (Adhitya, 2015: 27).

Kesalahpahaman dalam memandang "orang Cina" ini dapat menyebabkan perpecahan, sehingga perlu adanya informasi yang akurat dan tepat mengenai ragam jenis etnis Cina. Salah satu media yang dapat digunakan untuk meluruskan persepsi yang salah mengenai konsep "orang Cina" adalah sastra. Seperti yang diketahui bersama, karya sastra adalah medium yang tepat untuk membahas fenomena yang berkembang di masyarakat.

Kevin Kwan adalah salah satu contoh pengarang yang memberikan gambaran sangat jelas mengenai etnis Cina pada karya-karyanya. Ia mampu memberikan gambaran mengenai perbedaan-perbedaan yang ada pada etnis Cina, baik yang tinggal di RRC maupun etnis Cina yang tinggal di luar RRC.

Kwan sendiri adalah lahir di keluarga terpandang keturunan Cina-Singapura.
Pada saat ia berusia 12 tahun, ia dan keluarganya pindah dan menetap di Houston, Texas. Pada saat ini ia menetap di Manhattan, New York (Wong, 2013: par.16). Menyaksikan kesalahpahaman dalam pengambaran sosok "orang Cina" di media-media Barat, maka ia memutuskan untuk menyebarluaskan pengambaran yang benar mengenai apa dan siapa itu “orang Cina”. Pengalaman hidup Kwan sebagai etnis keturunan Cina yang tinggal dan tumbuh di 2 belahan dunia yang berbeda, Timur dan Barat, memberikannya fakta-fakta akurat mengenai perbedaan sosial-kultural yang ada diantara kelompok-kelompok etnis Cina.

Pada karyanya yang diterbitkan pada tahun 2016, yang berjudul China Rich Girlfriend (lanjutan serial Crazy Rich Asians, yang terbit di tahun 2013), yang kemudian diterjemahkan dalam Bahasa Indonesia oleh Cindy Kristanto menjadi Kekasih Kaya Raya yang terbit di tahun 2017, Kwan masih mengeksplorasi cerita mengenai orang-orang Cina-Singapura yang terpandang, lengkap dengan gaya hidupnya yang mewah. Tokoh utama pada novelnya yang terdahulu kembali dihidupkan kembali pada seri Kekasih Kaya Raya, disertai dengan kehadiran karakter-karakter baru seperti keluarga Rachel di California dan keluarganya yang baru ia temukan di Shanghai. Kedua kota 
di atas juga digunakan sebagai setting tempat berjalannya cerita, selain kota Singapura dan Hong Kong. Selain itu, novel ini juga menceritakan sosok orangorang Cina dari cara pandang orang-orang Cina sendiri. Hal ini mempermudah pembaca novel Kwan dalam melihat penggambaran orang Cina yang tinggal di RRC, Singapura dan Amerika. Oleh karena itu, novel ini adalah medium yang tepat untuk memberikan gambaran berbeda mengenai sosok etnis Cina, khususnya warga keturunan CinaAmerika, Cina-Singapura dan Cina daratan.

Melihat hal tersebut di atas, penelitian ini bermaksud untuk membahas mengenai topik multikulturalisme dengan menunjukkan beragam gambaran mengenai etnis Cina, seperti warga keturunan Cina-Amerika, Cina-Singapura dan Cina Daratan, seperti yang dapat ditemukan di novel Kwan yang berjudul Kekasih Kaya Raya. Dengan adanya penelitian ini, diharapkan dapat meluruskan kesalahpahaman yang berkembang mengenai konsep "orang Cina”, sehingga masalah-masalah rasial dan etnik dapat dihindari.

\section{Metode}

Teks sastra adalah medium penggambaran manusia dan kehidupannya yang disampaikan melalui bahasa (Kress pada tulisan Bearne, 2005: 288). Istilah 'penggambaran/representasi' dijelaskan oleh salah seorang tokoh teori budaya bernama Stuart Hall dalam bukunya yang berjudul Representation: Cultural Representations and Signifying Practices (1997). Akan tetapi, sebelum menggali lebih dalam mengenai teori Hall, istilah 'budaya' harus dikonseptualisasi terlebih dahulu karena representasi merunut pada dan oleh konteks dari suatu budaya tertentu. Budaya merupakan sistem cara hidup sehari-hari yang melibatkan perasan, ikatan dan emosi yang dipraktikan oleh satu kelompok sosial dalam periode waktu tertentu (Hall, 1997: 2). Oleh karenanya budaya tidak statis, melainkan dinamis dan berubah-ubah, terutama di era globalisasi yang memungkinkan keragaman budaya melebur, dan kemudian menciptakan multikulturalisme (Procter, 2013: 2). Kedinamisan budaya lalu mempengaruhi representasi dalam teks sastra.

Secara luas, representasi dapat diartikan sebegai sesuatu hal yang dapat menggantikan sesuatu hal yang lain yang secara keseluruhan diterima oleh masyarakat tertentu yang berada dalam satu budaya. Proses representasi memproduksi dan menukar makna, simbol dan gambar di antara orang-orang dalam suatu masyarakat tertentu (Hall, 1997: 10). Hall menawarkan tiga pendekatan untuk 
menganalisis representasi, yaitu reflektif, intensional dan konstruksionis. Namun, hanya pendekatan konstruksionis yang merupakan pendekatan yang paling tepat untuk menemukan makna di balik representasi budaya.

Pendekatan konstruksionis menekankan aspek sosial pada bahasa dan menganggap bahwa tidak ada makna tetap untuk sesuatu hal dalam masyarakat atau budaya. Hall menekankan perbedaan antara dunia material dan dunia simbolis. Yang pertama mengacu pada hal, ide, kejadian atau orang tertentu, sedangkan yang terakhir mengacu pada tanda-tanda representasional, yaitu bahasa, simbol, kode dan gambar (Hall, 1997: 5). Dunia material tidak dapat mengkonstruksi makna tanpa menggunakan tanda-tanda representasional dari dunia simbolis. Karena tanda-tanda representasi bergantung pada interaksi sosial dan fenomena budaya, yang terus berubah, makna hanya bisa dibangun dengan menganalisis konstruksi tanda tersebut. Menurut Hall (1997: 25),

Constructivists do not deny the existence of the material world. However, it is not the material world which conveys meaning: it is the language system or whatever system we are using to represent our concepts. It is social actors who use the conceptual systems of their culture and the linguistic and other representational systems to construct meaning, to make the world meaningful and to communicate about that world meaningfully to others.

Pendekatan konstruktsionis Hall berakar dari dua teoretikus berbeda, yaitu teori semiotika Ferdinand de Saussure dan teori wacana Michel Foucault. Dalam penelitian ini, pendekatan Hall terhadap semiotik digunakan untuk menganalisis penggambaran karakter-karakter Cina. Pada umumnya, semiotika dapat didefinisikan sebagai penelitian ilmiah terstruktur untuk menganalisis sistem representasi dalam lingkup budaya untuk memahami maknanya (Jensen, 2014: 1920). Hall mengutarakan bahwa (1997: 34):

Saussure's great achievement was to force us to focus on language itself, as a social fact; on the process of representation itself; on how language actually works and the role it plays in the production of meaning. In doing so, he saved language from the status of a mere transparent medium between things and meaning. $\mathrm{He}$ showed, instead, that representation was a practice.

Dalam lingkup budaya, representasi sangat penting dalam penyampaian makna, yang pada saat bersamaan memungkinkan budaya itu sendiri untuk dianalisis (Hall, 1997: 36). Dengan demikian, pendekatan semiotik berfokus pada tanda representasi. 'Tanda' terdiri dari signified dan signifier, yang tidak dapat dipisahkan karena keduanya berfungsi bersama. Signified adalah konsep atau ide sesuai yang tercetus di kepala seseorang, atau 
representasi mental. Sementara itu, signifier adalah bentuk tanda yang digunakan untuk mengacu pada konsep tersebut, juga dikenal sebagai sistem representasi (Saussure in Hall, 1997: 32).

Untuk memahami makna di balik representasi, penting untuk menghubungkan sistem representasi tanda ke konsep-konsep dalam representasi mental. Kedua konstituen representasi hanya dapat didefinisikan melalui sistem relatives dan differences, salah satunya adalah melalui oposisi binari (Saussure in Culler, 1976: 19). Seperti untuk menafsirkan representasi, proses encoding dan decoding juga diperlukan. Encoding menghubungkan makna dengan sistem representasi, dan decoding digunakan untuk mengkonstruksi makna (Hall, 1997: 62). Dengan menganalisis sistem representasi bahasa dalam membangun makna representasi mental, perbedaan dalam penggambaran keturunan Cina Daratan, Cina Singapura dan Cina Amerika dapat disoroti.

Data utama dalam penelitian ini diambil dari novel terjemahan Kevin Kwan's China Rich Girlfriend (2015) Kekasih Kaya Raya. Data yang dikumpulkan berupa kata, frase, klausa, kalimat dan paragraf, yang berhubungan dengan penggambaran yang berbeda antara orang-orang keturunan Cina Amerika,
Cina Singapura dan Cina Daratan. Dalam proses pengumpulan data digunakan teknik pembacaan komprensif serta pencatatan yang intensif yang sama persis seperti apa yang tertulis di novel.

Data yang telah dikumpulkan dianalisis menggunakan teknik qualitatif deskrptif dengan landasan teori representasi milik Stuart Hall. Selanjutnya, validitas data diperoleh dengan menggunakan teknik validasi semantik untuk menilai makna interpretatif berdasarkan konteksnya. Sementara itu, reliabilitas data dicapai menggunakan teknik intra-rater dengan cara membaca ulang data dan makna interpretatifnya.

\section{Hasil dan Pembahasan}

Representasi mental dalam benak khalayak tentang keturunan Cina dikonstruksi oleh Kevin Kwan dalam novel terjemahan Kekasih Kaya Raya melalui penggunaan sistem representasi, yaitu bahasa. Dengan tujuan untuk menyoroti penggambaran yang berbeda dari Cina Amerika, Cina Singapura dan Cina Daratan dalam novel ini, analisis dilakukan dengan memusatkan perhatian pada representasi karakter mengenai perilaku ekonomi dan pandangan dunia mereka. Dari kedua fokus ini, temuan penelitian ini akan dapat menekankan perbedaan antara keturunan Cina Amerika, Cina Singapura dan Cina daratan pada tingkat sosial budaya. 


\section{Perilaku Ekonomi}

Karena novel ini berkisah tentang keturunan Cina kelas elit, salah satu cara untuk meneliti penggambaran karakter keturunan Cina adalah melalui representasi perilaku ekonomi mereka, terutama pandangan dan sikap mereka terhadap uang. Demonstrasi 'kekayarayaan' yang mengelilingi kehidupan mereka mengisi sebagian besar isi novel karya Kwan. Ratusan halaman novelnya mempertontonkan kekayaan yang dimiliki oleh kaum elit ini, yang seolah-olah tak ada habisnya. Novel ini juga menggambarkan cara berbusana, perhiasan, karya seni, real estate dan pesta-pesta yang sering dihadiri oleh keturunan Cina kelas atas. Namun, ada penggambaran khas dari masing-masing karakter keterurunan Cina tersebut. Penggambaran karakter mereka dipengaruhi oleh latar belakang sosiobudaya tempat mereka bermukim.

Serti yang telah diketahui bersama,keturunan Cina telah tinggal di Amerika Serikat selama beberapa generasi. Meski negara ini dikenal luas sebagai negara yang makmur, keturunan Cina Amerika tidak hidup sesuai dengan budaya konsumtif negara adidaya tersebut. Perilaku ekonomi karakter keturunan Cina Amerika dalam novel digambarkan sebagai sosok yang pintar berhemat.
Mereka menggunakan uang dengan hatihati dengan hanya membeli barang yang mereka butuhkan dan bukan yang mereka inginkan. Bahkan ketika mereka membeli barang mewah, barang sedang diobral atau diskon besar-besaran.

“... Aku masih tidak percaya Nick membawamu ke Paris untuk membeli gaun dan akhirnya kau malah menemukan ini di diskon gaun contoh Temperley di SoHo!"

"Aku hanya tidak jatuh cinta dengan yang ada di Paris. Setiap gaun yang aku lihat musim ini begitu berlebihan, dan aku benar-benar tidak mau berurusan dengan kerepotan gaun adibusana-tahu kan, harus terbang bolak-balik ke Paris untuk mengepas," Rachel berkata agak malu.

"Oh anak malang menderita sekali, harus ke Paris untuk mengepas!" goda Sylvia (Kwan, 2017: 122).

Ketika mempersiapkan pernikahannya dengan Nick, pria yang berasal dari keluarga yang kaya raya, Rachel lebih memilih gaun pengantin yang dijual di department store daripada gaun desainer dari Paris. Keputusan ini dipengaruhi perilaku ekonominya yang irit karena sebagai keturunan Cina Amerika, masa kecil Rachel serba kekurangan. Dia tidak lahir di Amerika Serikat; ibunya, Kerry, berimigrasi saat Rachel masih bayi. Saat ia tumbuh dewasa, ia harus langsung menghadapi kesulitan hidup sebagai imigran, di mana ia dan ibunya harus memulai kembali kehidupan dari nol. Kerry, yang hanya lulusan SMP, tidak 
memenuhi syarat untuk pekerjaan yang layak dan hanya bisa mencari uang dengan menjadi buruh.

Kesulitan hidup yang harus dihadapi oleh keturunan Cina Amerika sudah terjadi semenjak alur imigrasi dari Daratan Cina dibuka secara besar-besaran pada tahun 1820 dengan harapan mendapat pekerjaan yang layak di Amerika Serikat. Karena kurangnya keterampilan, mereka akhirnya tinggal di Chinatown dengan taraf hidup rendah dan bertahan hidupdengan menjadi buruh. Namun demikian, mereka bersedia bekerja dengan upah rendah dan harus mengalokasikan uang mereka dengan bijak untuk memenuhi kebutuhan sehari-hari ("The National Park Service", 2004: par.4). Bahkan setelah satu abad berlalu, fakta ini masih mempengaruhi pandangan keturunan Cina Amerika terhadap uang. Mereka lebih suka menghemat uang sehingga mereka mampu untuk mendaftar di sekolah terbaik, daripada menghabiskan uang untuk barang mewah. Sikap hemat tersebut berkontribusi terhadap kemajuan finansial dan taraf hidup mereka, sehingga keturunan Cina Amerika sering diganggap sebagai model minority atau contoh sukses bagi kelompok minoritas lainnya di Amerika Serikat (Wu, 2014: par.7).

Berbeda dengan keturunan Cina Amerika yang menjadi kaum minoritas di negaranya, keturunan Cina di Singapura adalah mayoritas. Karenan mereka memiliki posisi penting di pemerintahan. Keturunan Cina Singapura memiliki kuasa atas kebijakan politik dan ekonomi negara tersebut. Hak istimewa ini memberi mereka kesempatan untuk mengumpulkan uang secara besar-besaran. Meski memiliki kekayaan berlimpah, perilaku ekonomi keturunan Cina Singapura dalam novel Kwan digambarkan dengan sebagai sosok kaya raya yang penuh dengan kerahasiaan. Tokoh-tokoh kaya raya pada novel Kwan tidak pernah mengumbar kekayaan mereka kepada teman apalagi musuh. Mereka juga tidak membual tentang asset, properti atau investasi yang mereka miliki.

"Sekarang, bisakah aku mengandalkanmu untuk berahasia?" tanya Eleanor, menatap lurus ke matanya.

"Aku tidak tahu apa yang kaubicarakan, Bibi Elle," sahut Eddie sambil nyengir.

"Aku bicara soal sarapanku... tadi pagi?"

"Oh, jangan khawatir, aku sudah lupa soal itu. Aku disumpah untuk menjaga rahasia ketika bergabung dengan dunia bank swasta, dan aku tidak pernah bermimpi untuk mengkhianatinya. Di Grup Liechtenburg, apa yang dapat kami tawarkan selain kerahsiaan dan kepercayaan?"

Eleanor kembali ke dalam restoran, merasa agak lega dengan keadaan yang berbalik tanpa disangka-sangka ini. Dia dapat menyamakan skor dengan keponakannya. (Kwan, 2017: 26) 
Eleanor mendadak cemas ketika tak sengaja bertemu dengan keponakan suaminya, Eddie, saat di Inggris. Alasannya adalah karena kejadian tersebut terjadi di bank investasi, yang berarti Eddie mengetahui bahwa Eleanor memiliki investasi di bank tersebut. Eleanor meminta Eddie untuk merahasiakan kejadian itu karena Eleanor bilang ke teman-temeannya dia hanya pergi untuk sarapan dengan saudaranya yang tinggal di Surrey. Terlepas dari kekayaan suami dan mertuanya, Eleanor sendiri berasal dari keluarga terhormat dan kaya, sehingga dia mempunyai hak penuh atas kekayaannya sendiri dan memiliki otoritas dalam pengelolaannya. Meskipun, dia sering boros dengan menghabiskan uangnya untuk memenuhi seleranya yang tinggi, tapi dia juga selalu dengan cerdas menghemat untuk membeli aset atau berinvestasi.

Sama dengan karakter keturunan Cina Singapura lainnya dalam novel ini, Eleanor sangat tertutup mengenai hartanya. Dia merahasiakan aset dan investasi dari teman-temannya, bahkan dari keluarganya sendiri. Sikap diam-diam terhadap kekayaan ini sangat dipengaruhi oleh kebijakan pemerintah Singapura, yang tertuang pada Undang-Undang Perbankan Singapura (UU 41 th. 1970) yang diberlakukan beberapa saat setelah kemerdekann negara tersebut. Selain itu, perilaku ekonomi mereka yang tertutup juga membuat keturunan Cina Singapura jarang muncul dalam daftar orang-orang kaya yang dibuat oleh majalah-majalan finansial. Hal ini bisa digunakan untuk membedakan mereka dari keturunan Cina Daratan. Keturunan Cina Singapura menganggap pencantuman nama-nama dalam daftar kekayaan semacam itu sangalah berlebihan, sementara keturunan Cina Daratan terobsesi dengan hal itu (Kwan di Connelly, 2013: par.27). Selain itu, karena 'kekayarayaan' mereka sudah diperoleh semenjak beberapa generasi sebelum mereka, keturunan Cina Singapura menganggap diri mereka sebagai Old Money, dan menganggap keturunan Cina Daratan sebagai New Money.

Keturunan Cina Daratan terbiasa hidup dengan sistem feodal kuno karena mereka bermukim di tanah leluhur mereka, Namun seiring masuknya paham komunisme, perbedaan tradisional kelas masyarakat merubah Cina Daratan menjadi negara yang rakyatnya memiliki posisi dan hak yang setara. Perubahan ini memberikan pengaruh pada pertumbuhan keluarga kelas menengah. Meski begitu, perbedaan sosial tetap ada. Keluarga kelas menegah di Cina Daratan masih menganggap diri mereka miskin karena 
terlepas dari kenyataan bahwa mereka dapat hidup berkecukupsn, tidak mungkin bagi mereka untuk hidup bergelimang kemewahan seperti yang dimiliki keluarga kelas atas yang kaya raya. bersumber dari pemahaman inilah, maka perilaku ekonomi karakter keturnan Cina Daratan yang kaya dalam novel digambarkan boros. Mereka tidak dapat menahan diri untuk tidak menghambur-hamburkan uang, terlebih jika orang lain melihat saat mereka melakukannya.

Tiga puluh detik kemudian, palu diketuk untuk The Palace of Eighteen Pefections. Dengan harga [USD] 195 juta, itu adalah karya seni Cina paling mahal yang pernah dijual dalam pelelangan. Kerumunan glamor itu meledak dalam tepuk tangan yang menulikan ketika Kitty Pong bergaya di depan kamera, lampu kilat menyambar-nyambar seperti ledakan di kota Kabul ... Sekarang seluruh dunia tahu bahwa Kitty Pong-atau Mrs. Bernard Tai, begitulah dia ingin disebut disebut saat ini-benar-benar sudah tiba (Kwan, 2017: 43).

Kitty membeli sebuah lukisan yang dilelang dengan bandrol sangat mahal. Walaupun dia telah menikah dengan pria keturunan Cina Hong Kong, namun perilaku ekonominya tetap dipengaruhi pola pikir dari kampung halamannya, yakni Cina Daratan. Di dalam novel, karakter keturunan Cina Daratan digambarkan sebagai sosok yang benarbenar boros. Mereka membeli properti di seluruh dunia, mengendarai mobil sport buatan Eropa, mengumpulkan barang mewah dan mengoleksi karya seni klasik yang berharga mahal seperti yang diilustrasikan diatas.

Sikap vulgar keturunan Cina Daratan terhadap uang dipicu oleh 'gengsi' yang dimilik lingkunag masyarakatnya. Penilaian terhadap seseorang didasarkan sepenuhnya pada penilaian orang lain (Wilkinson, 2016: par.6). Untuk mendapatkan posisi dan kekuatan sosial, mereka harus memamerkan uang dengan hidup dalam perilaku yang boros. Hal ini didesak oleh kebutuhan untuk memvalidasi kekayaan mereka dengan menunjukkan apa yang bisa mereka beli dan memamerkannya kepada orang lain. Dengan demikian, upaya mengumpulkan dan memamerkan uang bisa mungkin untuk mendukung dan mengangkat citra diri dan keluarga, karena bagi mereka hal tersebut merupakan prioritas utama.

\section{Pandangan Dunia (World View)}

Tersebar di berbagai belahan dunia, setiap kelompok sosio-kultural keturunan Cina memiliki pandangan dunia yang berbeda sebagai dorongan paling mendasar, yang membentuk bagaimana mereka mendefinisikan realitas dan menguraikan tujuan hidup. Bagaimana keturunan Cina di Amerika Serikat, Singapura dan Cina Daratan melihat dunia dibangun oleh budaya dan politik masing- 
masing negara. Praktik budaya dan politik masing-masing negara sangat mempengaruhi pandangan dunia dari keturunan-keturunan Cina tersebut. Perbedaan pandangan dunia keturnan Cina Amerika, Cina Singapura dan Cina Daratan dapat dianalisis melalui penggambaran karakter-karakter keturuan Cina dalam novel.

Sebagai negara yang warganya terdiri dari imigran-imigran, Amerika Serikat menerapkan nilai kolektif untuk menyatukan kultural dan ras yang beragam. Salah satu nilainya adalah egalitarianisme, yang sangat dipegang teguh oleh keturunan Cina Amerika. Keyakinan mereka yang kebarat-baratan terhadap nilai egaliter telah membantu mereka untuk sukses dan memili taraf hidup yang lebih baik dari kelompok ras lainnya di Amerika Serikat. Pandangan dunia dari karakter keturunan Cina Amerika dalam novel digambarkan sebagai penganut paham egalitarianisme. Mereka yakin kalau mereka memiliki kesempatan yang sama seperti kelompok ras lainnya dalam mencapai kesejahteraan dalam hal perkonomian, akademis, sosial dan keagamaan,

“... Apa yang kaulakukan ketika berumur 23?”...

Rachel menenangkan diri dan melanjutkan, "Waktu umur 23 tahun, aku berada di Chicago mengambil kuliah pascasarjana di Northwestern.
Dan aku menghabiskan setengah tahun di Ghana." (Kwan, 2017: 348349)

Salah satu cara untuk melepaskan diri dari kesulitan hidup sebagai imigran di Amerika Serikat, keturunan Cina Amerika, seperti Rachel dan ibunya, adalah melalui kemajuan akademis. Kerry bekerja keras untuk bisa menyekolahkan Rachel dan dirinya sendiri hingga perguruan tinggi di universitas-universitas terkemuka di Amerika Serikat. Keturunan Cina pada umumnya dikenal rajin, pekerja keras dan bersungguh-sungguh pada apa yang mereka kerjakan. Selain itu, pengaruh nilai egaliter dalam pandangan dunia keturunan Cina Amerika mendorong mereka untuk bekerja dua kali lebih keras dari orang lain, yang pada akhirnya memperbaiki kemampuan finasial mereka.

Konsep egalitarianisme berasal dari dasar agama, yang menunjukkan bahwa semua manusia diciptakan sama, tanpa memandang ras, etnis, agama atau asal usulnya. Sebagai pandangan dunia, egalitarianisme memiliki kemampuan untuk menetapkan panduan yang mengatur tindakan dan interaksi masyarakat Amerika yang diarahkan oleh keyakinan bahwa semua orang memiliki kesempatan yang sama untuk sukses dalam kehidupan, jikalau mereka mau untuk bekerja keras dan memiliki tekad yang kuat. Masyarakat Amerika, termasuk keturunan Cina 
Amerika, mungkin memiliki pandangan individu yang berbeda tentang bagaimana mengubah cita-cita ini menjadi realita. Namun, mereka semua sangat setuju bahwa persamaan adalah nilai kolektif yang esensial (Kohls, 1984: 3). Sejak jatuhnya pasar saham pada tahun 1929, egalitarianisme telah dipahami sebagai benih dari American Dream. Untuk membantu masyarakat Amerika menghadapi Great Depression pada tahun 1930an, cerita-cerita orang miskin yang menjadi kaya raya banyak bermunculan.

Kisah sukses semacam itu jarang terdengar di kalangan keturunan Cina Singapura. Mayoritas keturunan Cina Singapura yang kaya sudah memiliki harta mereka dari beberapa generasi sebelummnya. Untungnya, mereka selalu berhasil mengembangkan warisan mereka menjadi kekayaan yang lebih besar lagi. Salah satu kunci kesuksesan mereka adalah Shared Values, yang telah mempengaruhi bagaimana keturunan Cina Singapura memandang dunia (Seng, 2017: par.1). Pandangan karakter keturunan Cina Singapura dalam novel digambarkan dengan komunitarianisme dan individualisme. Mereka adalah individu yang berpikiran bisnis yang mengklaim mengutamakan kemajuan bangsa diatas golongan, dan memprioritaskan kesejahteraan bersama di atas kepentingan pribadi. Ketika mereka berhasil, mereka ikut menaikan derajat keluarga dan membantu anggota kelurgaa yang lain untuk menjadi sukses juga.

Seorang ahli dalam garis keturunan Asia Tenggara (yang tidak ingin disebutkan namanya) berkata, "Kita tidak akan pernah menemukan keluarga Leong dalam daftar mana pun karena mereka jauh terlalu pandai dan terlalu hati-hati untuk terlihat. Mereka adalah keluarga Cina Peranakan yang luar biasa tertutup, garis keturunannya sudah beberapa generasi, dan memiliki beragam perusahaan di seluruh Asia-bahan baku, komoditi, real estate, semacam itu. Kekayaan mereka sangat besarkakek buyut Astrid, S.W. Leong, dulu dijuluki 'Raja Kelapa Sawit dari Borneo'. Jika Singapura memiliki aristokrasi, Astrid akan dianggap putri kerajaan." (Kwan, 2017: 340-341)

Disamping kekayarayaan yang diwarisi dari keluarganya, Harry Leong adalah seorang pengusaha yang sangat sukses. Selain itu, ia juga bekerja di pemerintahan Singapura, yang memberinya posisi penting dalam pembuatan kebijakan negara. Dengan demikian, dia bisa mengusulkan atau mendukung kebijakan ekonomi atau politik yang hanya menguntungkan perusahaan-perusahaannya. Namun, dalam berbagai kesempatan, dia menyebut dirinya sendiri hanyalah seorang "pegawai negeri", yang tidak peduli dengan bagaimana citranya di tengah masyarakat elit (Kwan, 2017: 359). Terlepas dari 
kekayaan dan posisinya dalam pemerintahan, dia percaya bahwa dia berbuat baik untuk kesejahteraan negara dan warganya. DI sisi lain, dia secara besar-besaran memanfaatkan posisinya untuk keuntungan pribadi dan keluarganya.

Selanjutnya, Shared Values digunakan sebagai pandangan dunia semu untuk menyatukan masyarakat Singapura. Awalnya, nilai-nilai nasional tersebut diusulkan untuk menghalau "pandangan yang kebarat-baratan, individualistik, dan mengutamakan kepentingan diri sendiri” (Seng, 2015: par.3). Dengan cara ini, pemerintah mengendalikan alat-alat produksi utama, seperti perusahaan perumahan dan bisnis utama yang dimiliki pemerintah. Namun, ketergantungan negara terhadap aktivitas perdagangan menunjukkan bahwa Singapura mengadopsi sistem kapitalisme di sektor ekonominya. Dengan demikian, Singapura adalah negara yang menganut paham statecapitalist (Adhitya, 2015: 42).

Saat banyak dari warga negara Republik Rakyat Cina melarikan diri ke negara-negara seperti Singapura dan Amerika Serikat sebelum pengambilalihan oleh partai Komunis, banyak juga warga yang memilih untuk tetap tinggal di sana dan telah terpengaruh oleh paham Komunisme. Nilai-nilai komunisme ternyata tidak bertentangan dengan nilai tradisional keturunan Cina Daratan, seperti Konfusianisme. Pada gilirannya, nilai-nilai tersebut mempengaruhi cara orang-orang Cina Daratan melihat dunia. Pandangan dunia karakter-karakter keturunan Cina Daratan dalam novel digambarkan dengan Konfusius-Komunisme. Mereka bekerja tanpa pamrih bukan untuk keuntungan pribadi, tapi demi kesejahteraan keluarga dan negaranya.

“... Ibuku terbiasa dengan jalan hidup yang sangat teratur, dan dia menghabiskan bertahun-tahun merencanakan semuanya dengan sempurna. Seperti perusahaan itu. Dan karir Ayah. Dia benar-benar kekuatan di balik keberhasilan politik Ayah, dan sekarang dia juga mencoba mempersiapkan masa depanku. ..."

"Tapi apa yang direncanakannya untukmu? Apakah dia ingin kau juga terjum ke politik?"

"Pada akhirnya, ya."

"Tapi apakah kau menginginkannya?" Carlton mendesah. "Aku tidak tahu apa yang kuinginkan." (Kwan, 2017: 348).

Salah satu karakter keturunan Cina Daratan, bernama Carlton, yang merupakan saudara tiri dari Rachel, terbebani oleh ibunya, Bao Shaoyen, yang menginginkannya untuk terjun dalam ranah politik Cina, seperti ayahnya, Bao Gaoliang. Carlton sendiri saat itu sedang menempuh studi pascasarjana di Universitas Oxford dengan jurusan bisnis, sehingga dia tidak memiliki pengetahuan 
maupun ketertarikan pada bidang politik. Kendati demikian, dia tidak berani menolak keinginan ibunya karena akan dianggap sebagai tindakan yang kurang ajar. Baik keinginan Shaoyen maupun reaksi Carlton terjadi karena mereka melihat dunia melalui kacamata pandangan dunia komunis-konfuscius. Shaoyen ingin Carlton menjadi politisi karena di negara komunis, politisi memiliki status sosial lebih tinggi daripada masyarakat pada umumnya. Dalam lingkungan masyarakat seperti ini, menjadi politisi bisa menjadikan posisi strategis ditengah-tengah orang-orang yang berkuasa (Phillips dan Wisnewski, 2012: $67)$.

Di sisi lain, penolakan Carlton yang ragu-ragu terhadap keinginan ibunya dibentuk oleh nilai-nilai tradisional Konfusius yang berakar kuat di benak keturunan Cina Daratan. Konfusianisme adalah sistem kepercayaan filosofis, sosioekonomi, politik, dan etika. Salah satu penekan utamanya adalah pada pemeliharaan keharmonisan dalam keluarga, seperti bakti anak terhadap orang tua, yang mengajarkan rasa hormat kepada orang tua dan leluhur (Fingarette, 1972: 463-477). Pandangan dunianya membuat Carlton inferior dalam menghadapi ibunya sehingga dia merasakan paksaan dan tekanan bahwa apapun yang ibunya inginkan atau perintahkan harus dipatuhinya. Oleh karena itu, dia percaya bahwa terlibat dalam politik adalah tujuan hidup yang terbaik untuknya dan juga demi kesejahteraan bangsa.

\section{Simpulan}

Setelah melakukan analisis terhadap perilaku ekonomi dan pandangan dunia, penggambaran yang berbeda dari keturunan Cina Amerika, Cina Singapura dan Cina Daratan seperti yang tertuang dalam novel terjemahan karya Kevin Kwan berjudul Kekasih Kaya Raya dapat ditarik kesimpulan sebagai berikut: (1) keturunan Cina Amerika bersikap hemat dan egaliter; (2) keturunan Cina Singapura bersifat tertutup dan menganut paham state-capitalisme; dan (3) keturunan Cina Daratan menghabiskan banyak uang, serta menganut paham Konfusius-Komunis. Penemuan ini diharapkan bisa membuka mata masyarakat tentang multikulturalisme terhadap keturunan Cina, dan berkontribusi dalam mencegah perilaku rasial dan etnik terhadap mereka.

\section{Daftar Pustaka}

Adhitya, G. N. 2015. "The Revelation of Authorial Ideology through the Class Structure and Class Conflict Represented in Kevin Kwan's Crazy Rich Asians". Skripsi: Universitas Negeri Yogyakarta. 
Bearne, E. 2005. "Interview with Gunther Kress". Discourse: Studies in the Cultural Politics of Education. 26(3): 287-299.

Connelly, S. 2013. “Kevin Kwan's Novel 'Crazy Rich Asians' Eyes Split between Old and New Money in Singapore." New York Daily News. http://www.nydailynews.com/entertai nment/music-arts/bling-crazy-richasians-eyes-singapore-high-lifearticle-1.1371886. Diakses pada 7 April 2017.

Culler, J. 1976. Saussure. London: Fontana.

Dhani, Arman. "Rasisme terhadap Etnis Tionghoa dari Masa ke Masa" https://tirto.id/rasisme-terhadap-etnistionghoa-dari-masa-ke-masa-bZQN . Diakses pada 29 Agustus 2017.

Fingarette, H. 1972. "Confucius-The Secular as Sacred." Philosophy East and West. 26.4, pp. 463-477. Hawaii: The University of Hawaii Press.

Hall, S. 1997. Representation: Cultural representations and signifying practices. London: Sage.

Jensen, L. 2014. "Representations of Sherlock Holmes: A Study of Sherlock Holmes' New Trademarks as a Sex Symbol, Action Hero, and
Comedian in the $21^{\text {st }}$ Century". Thesis. Aalborg University.

Kohls, L. R. 1984. "The Values Americans Live By." https://careercenter.lehigh.edu/sites/ca reercenter.lehigh.edu/files/AmericanV alues.pdf. Diakses pada 6 April 2017.

Kwan, K. 2017. China Rich Gilfriend. Cindy Kristanto (trans.) Kekasih Kaya Raya. Jakarta: Kompas Gramedia.

Phillips, K. G., and J. J. Wisnewski. 2012. Arrested Development and Philosophy. New York: John Wiley \& Son.

Procter, J. 2013. Stuart Hall. London: Routledge.

The National Park Service. ParkNet. 2004. "A History of Chinese Americans in California".

https://www.nps.gov/parkhistory/onlin e books/5views/5views3.htm. Diakses pada 3 April 2017.

Seng, L. T. 2015. "Shared Values." National Library Board Singapore. http://eresources.nlb.gov.sg/infopedia/ articles/SIP 542_2004-12-18.html. Diakses pada 10 April 2017.

Wang, G. 1998. "The Status of Overseas Chinese studies. In L.-c. Wang \& G. Wang (Eds.), The Chinese Diaspora. Selected Essay. 1: 1-13. Singapore: Times Academic Press. 
Wilkinson, J. 2016. "Do Mainland Chinese

People Worship. Money?". Quora.

https://www.quora.com/Do-Mainland-

Chinese-people-worship-money.

Diakses pada 6 April 2017.

Wong, PP. 2013. "Kevin Kwan

Interview". Banana Writers.

http://www.bananawriters.com/\#!kevi

nkwaninterview/cluow. Diakses pada

18 Oktober 2014.

Wu, E. D. 2014. "Asian Americans and the

'Model Minority' Myth”. Los Angeles

Times. http://latimes.com/opinion/op-

ed/la-oe-0123-wu-chua-model-

minority-chinese-20140123-

story.html. Diakses pada 18 Maret

2017. 